\title{
A Study of Students Attitude towards the Three Categories of Questions in W.A.E.C. Practical Chemistry Examination in Zaria Inspectorate Division of Kaduna State, Nigeria
}

\author{
Muhammad Binta Asabe \\ Department of Chemistry, Federal College of Education, Zaria Kaduna State, Nigeria
}

\begin{abstract}
The study was designed to test students attitude towards the three categories of questions in WAEC practical chemistry examination. A survey research design was adopted were a questionnaire was administered to the target population. ANOVA one-way analysis of variance was used to analyse the data collected. It was found that; there is a significant difference in the student's attitude towards the three categories of questions in WAEC practical chemistry examination. Sheffes' test was administered to determine where the differences in attitude lie. It was found that; students have positive attitude towards theory of practicals followed by qualitative analysis, quantitative analysis was the least. Recommendations were made amongst which include: Students should be motivated and encourage in the area of quantitative and qualitative analysis.
\end{abstract}

\section{INTRODUCTION}

The past decades in doubt has been a period of pressure and movement towards educational reforms. However, in spite of the various innovations introduced into our educational system, achievement of the desired result remains an illusion. Thus in literatures one can find expressions of disquient on the teaching and learning of science (Orukotan and Balogun, 2000). Nigerian secondary school students' performance in science has been poor and unimpressive over the years (Muhammad, 2009). The National policy on Education (2007) emphasized that instructional strategies in all science shall be activity/practical based to enable learners appreciate science as a process. This arises due to the importance of practical in all science subjects because practical serves as the backbone of science.

Chemistry is one of the important science subjects taught to students at the senior secondary school level as rightly observed (Shaibu, 1998). It is one of the core science subject that a credit pass at ' $O$ ' level in it is a precondition for admission to pursue science based programmes at the tertiary level. It is so central that, nearly any area of scientific endeavour has an effect on chemistry and vice versa (Fatokun, 2006). Inspite of this important of chemistry among science related discipline students performance has consistently been below expectation and unimpressive (Adeniyi; 1997, Njoku; 2005, Jegede; 2010, Oloyede; 2010). A trend over time shows general poor performance in practical at SSCE (Muhammad; 2009).

A lot of work on SSSCE practical chemistry has been done. A number of factors have been identified as responsible for poor achievement in practical aspect of SSCE chemistry examination. Among those factors are students' attitude and interest. Students attitude towards a subject affects their understanding of the subject (Timothy; 2005). Attitude is a predisposition or a tendency to respond positively or negatively towards a certain idea, object, person, or situation. It influences an individual's choice of action, and responses to challenges, incentives, and rewards (together called stimuli). (Busines Dictionary; 2012). Therefore when students shows positive attitude towards practical chemistry it will enhance good conceptual understanding.

Jaynes (2005) states that students who are academically successful hold positive attitude in school and are well adjusted emotionally and socially. Olatoye (2001) found that students' attitude towards science have significant direct effects on students' achievement in the subject. Awareness of students' attitude towards practical chemistry is a critical factor worthy of consideration. Students' attitudes are taught to influence future behaviours and have implication for chemistry practicals since attitude is a way of feeling, thinking or behaviour towards a particular thing (Peterson, 2003). Halonene and Santrock (1996) views attitude as beliefs and opinions that can predispose an individual to behave in certain ways. In a nutshell, attitude comprises of both cognitive and affective components. Therefore, another way of assessing students' approach to chemistry practicals is by testing students' attitude towards it.

\section{Statement of the problems}

Practicals are vital aspects of chemistry curricula at senior secondary school levels that finds prominence in all chemistry examination. Performances of students in chemistry has consistently been poor and unimpressive (Njoku, 2005). The need to find solution to students' poor performance in chemistry is therefore obvious. West African Examination Council, Chief examiners' report (2007) noted students poor performance 
in practical chemistry. Therefore there seems to be no doubt that students have problems/difficulties with the practicals aspect of chemistry in SSCE. How can these problems be alleviated so as to enable students perform better in chemistry practical examination?

The alleviation of these problems according to Njoku (2007) would involve the identification and categorisation of the factors which affect students; performance in practical chemistry and manipulate such factors to the advantage of the learners. There is the need to investigate the attitude of students towards WAEC practical chemistry, which comprises of the theory of practicals, qualitative analysis and quantitative analysis.

\section{Research question}

In order to investigate the problem identified, the study specifically seeks to answer the following question: (1) What is the effect of students' attitude towards the three categories of questions in WAEC practical chemistry examination?

\section{Null hypothesis}

The null hypothesis for the study is as follows:

$\mathrm{H}_{0: 1}$ There is no significant difference in the attitude of students towards the three categories of questions in WAEC practical chemistry examination.

\section{Significance of the study} following ways.

It is hoped that the findings of this study would contribute to the learning of chemistry in the

The study will provide a means of minimizing the mass failure in practical chemistry by identifying the students' attitude towards the three categories of questions in WAEC practical chemistry. In areas where students have negative attitude there will be encouragement and motivation on the part of the teacher so that the students' interest would be aroused and at the end there will be improvement in the students' performance. The results of the study will be of immense benefit to science education planners, science based organisation so that necessary modifications will be made in the chemistry curriculum.

\section{Research design:}

\section{Research Methods}

The research design is a survey research where by a questionnaire was administered to the target population to determine their attitude in the three categories of questions asked at WAEC practical examination.

\section{Population of the study}

The population of the study comprises (582) SSIII Science students in the public senior secondary schools under Zaria Educational Zone Inspectorate division Kaduna State, Nigeria. The population comprises of single sex and co-educational schools; there are four (4) males schools, five (5) females schools and eight (8) co-educational schools in the population. The age - range of the students is between 16- 19 years old.

\section{Sample and sampling procedure}

A sample of fifty students was sampled from the total of 582 students using simple random sampling, this sample confirms to that recommended by Fraenkel and Wallen (2000) of 30 subjects as the minimum sample size.

\section{Instrumentation}

The instrument for data collection is students' attitude inventory (SAI) questionnaire in the three categories of questions in WAEC practical chemistry examination. The instrument was developed by the researcher and validated by experts in chemistry, science education and psychology. Two lecturers from the Department of Chemistry, Ahmadu Bello University Zaria. A lecturer from Science Education Department, Faculty of Education, Ahmadu Bello University and a lecturer from educational psychology Department, Ahmadu Bello University Zaria participated in the validation. The questionnaire contained seven (7) items on theory of practicals, ten (10) items in qualitative analysis and eight (8) items in quantitative analysis respectively..

The questionnaire was divided into two sections; Section A which comprises of students' personal data response while section B consists of a 5-point Likert scale responses (i.e. strongly agree, agree, undecided, disagree, strongly disagree) which is on students' attitude towards the three categories of questions in WAEC practical chemistry examination. The reliability of the instrument was estimated by split half method using Pearson product moment correlation coefficient (PPMCC) statistics and Spearman-Brown prophecy formula. This formula yielded a reliability of 0.83 . 


\section{Procedure for data collection}

The researcher distributed the students' attitude inventory questionnaire to the study sample. The students were allowed to read through the written instruction on how to respond to the items of the questionnaire. The instruction was explained to the subjects verbally and they are allowed to ask questions for further clarifications. The subjects spent about 40 minutes in completing the questionnaire, in all the schools, the researcher was assisted by the chemistry teacher to ensure cooperation of the subjects. After the students have completed their responses, the questionnaire was collected and subjected to data analysis.

\section{Data analysis technique}

The data generated from the chemistry practical attitude questionnaire were analysed using ANOVA one way analysis of variance, since the students' attitude on the three aspects of practicals was being investigated, i.e. students' attitude towards quantitative analysis, qualitative analysis and theory of practical. The significant level for the rejection or acceptance of the hypothesis is $\mathrm{p} \leq 0.05$.

\section{Results Analysis and Discussion}

The study aims at investigating the effects of students' attitude towards the three categories of questions in WAEC practical chemistry examination. And for the hypothesis which states that $\mathrm{H}_{\mathrm{o}: 1}$ there is no significant difference in the attitude of students towards the three categories of questions in WAEC practical chemistry. Summary of the analysis is presented in Table 1.1.

Table 1.1: Analysis of variance of students' attitude towards the three categories of questioning in WAEC practical chemistry examination.

\begin{tabular}{|lllllll|}
\hline Source of variation & Sum of squares & df & Mean of squares & F & Sig. P & Remarks \\
\hline Between groups & 4.714 & 2 & 2.357 & 8.39 & 0.001 & Significant \\
\hline Within groups & 40.626 & 144 & 0.282 & & & \\
\hline Total & 45.339 & 146 & & & & \\
\hline
\end{tabular}

From Table 1.1, P-value of 0.001 is less than the set alpha value of 0.05 which means that there is a significant difference in the attitude of students towards three categories of questions in WAEC practical chemistry. Therefore, the null hypothesis is rejected and since there is a significant difference, post hoc test will be administered to see where the difference actually occurs. The difference may be as a result of the content in each category which varies, therefore this may lead to the differences in student's interest.

Table 1.2: Scheffes test showing paired sample statistics

\begin{tabular}{|l|l|l|l|l|l|}
\hline & & Mean & $\mathrm{N}$ & Std deviation & Std errors mean \\
\hline Pair & Theory & 3.2828 & 49 & 0.6209 & 0.8871 \\
\hline 1 & Quantitative & 3.1516 & 49 & 0.5988 & 0.7155 \\
\hline Pair & Theory & 3.2828 & 49 & 0.62098 & 0.8871 \\
\hline 2 & Qualitative & 2.8546 & 49 & 0.45811 & 0.6544 \\
\hline Pair & Qualitative & 3.1510 & 49 & 0.50088 & 0.7155 \\
\hline 3 & Quantitative & 2.8540 & 49 & 0.45811 & 0.6544 \\
\hline
\end{tabular}

Table 1.2 above, shows that; theory of practical has the highest mean of 3.28 followed by qualitative analysis with mean of 3.15 and quantitative analysis has the least mean of 2.85 . Therefore the students' positive attitude towards the theory of practical is highest, this might be due to the fact that the question was designed to assess students' knowledge of techniques, principles and expected observations during chemistry laboratory activities the question assessed cognitive thinking skills and ability in interpretation of data and making inference. The theory of practical deals mainly with the cognitive and theoretical concepts that underlie the practical activities to be conducted.

Qualitative analysis is the next and it requires students to identify a mixture of two salts through a systematic series of tests for the constituent ions. This aspect assessed students' skills in problem identification, conducting of experiment, manipulation of equipment, hypothesizing, careful observation, interpretation of observation making of inference/deductions, organisation and recording of data and effective communication of findings 
Finally the students have least mean in quantitative analysis which requires the student to estimate the concentration of the acid and base in moles and grammes per $\mathrm{dm}^{3}$ respectively, as well as the volume of acids that would produce one mole of the resultant salt in the equation. It was designed to assess students' skills in conducting experiments, manipulation of equipments, measurement of volumes, careful observation, control of variables and recording of data, this study is in line with the findings of Muhammad (2009) and is contrary to the findings of Njoku (2007).

\section{Summary and Conclusion}

The result of the research shows that there is a significant difference in the attitude of students toward the three categories of questions in (WAEC) practical chemistry as they have more positive attitude towards theory of practical followed by qualitative analysis.

\section{Recommendations}

(1) Chemistry laboratories should be adequately equipped to ensure a smooth running of the practical classes and students should be encouraged in the qualitative analysis of chemistry practical and appropriate motivation should be given so that they will develop positive attitude towards qualitative analysis.

(2) Chemistry teachers should be given incentives so that they will be motivated to put more effort in the practical classes.

\section{REFERENCES}

[1] Adeyini E.O. and Landu, I.T. (1997) Women in National Development: The place of Science,

[2] Technology and Mathematics Educ. I G. A Badmus and L.A Echo (ed) Science and Mathematics and Technology education in Nigeria Academy of Education. 128-139 Lagos.

[3] Fatokan, K.V.F. (2006). Application of Computer aided instruction to the Teaching of 'mole' Concept in chemistry in senior Secondary school Syllabus, Journal of Chemistry Education, 79(2); 248 - 257.

[4] Federal Government of Nigeria (2007) (Revised) National Policy on Education

[5] Fraenkel J.R. \& Wallen N.E (2000). How to design an evaluate research in education. Mc Graw Hill, New York

[6] Halonen, J.S. and Santrock, J.W. (1996). Psychology context of behaviour. McGraw-Hill companies. P 222

[7] Jaynes, W.H. (2005). A meta of the relationship of parental involvement to elementary school student achievement, Urban Education, 40 (3); $237-269$.

[8] Jegede S.A. (2010) Nigerian Students Perceptions of Technical words in Senior Secondary School Curriculum. Pakistan Journal of Social Science Sciences 7(2), 109-111

[9] Muhammad, B.A. (2009). Accessing the process skill in practical chemistry of SSCE

[10] Students. A conference paper presented at the school of science National conference held at Federal College of Education, Zaria.

[11] Njoku, Z.C. (2005). Levels of Chemistry Practicals Skills Acquired by Senior Secondary Schools II SSII Students . Nigerian Journal of Professional Teachers 2 (1); 88.

[12] Njoku, Z.C. (2007). Comparison of students' achievement in the three categories of questions in SSCE practical chemistry examination. Journal Science Teachers Association of Nigeria, 42 (1 \& 2); $67-72$.

[13] Oloyede O.I. (2010). Enhance Mastery Learning Strategy on the Achievement and Self- concepts in Senior Secondary School Chemistry. Humanity \&Social Sciences Journal 5(1), 19-24.

[14] Online Business Dictionary 2012 retrieved from goggle 28/12/2012

[15] Orukotan, A.F. and Balogun, E.M. (2000). Implementing conceptual change: A strategy for $41^{\text {st }}$ Annual conference proceeding of Science Teachers' Association of Nigeria, $65-67$.

[16] Peterson, P.E. (2003). That school vouchers significantly improved test scores of black children. Education Section, New York Times May, 72003.

[17] Shaibu, A.A.M. (1998). A study of students' Academic achievement as a correlate of their competence in practical activity in chemistry. Niger educational forum. Journal of the Institute of Education, Ahmadu Bello University, Zaria, 14 (2); 33.

[18] Timothy J. (2005) Secondary Schools Students Attitude towards Animal Conservation. A case study of Selected Junior Secondary Schools in Zaria Metropolis. Nigerian journal of Science and Educational Research 1(2), 27-31.

[19] WAEC (2007). West African Examinations Council, Chief Examiners' report. Lagos Meg. Com. Network. 